\title{
Pemanfaatan Limbah Biogas Sapi sebagai Media Tanam Perbenihan Jambu Biji
}

\author{
Aryana Citra Kusumasari ${ }^{11}$ dan Muryanto ${ }^{1)}$
}

\begin{abstract}
Cow biogas waste can be used as guava organic fertilizer. The objective of this research was to determine the composition of the planting media from biogas waste for the best guava seedling. This research was conducted in Ungaran Barat, Semarang, Central Java from July-December 2015. The method used was Randomized Complete Block Design (RCBD) one factor that is the ratio of media compositions of 5 treatments, 4 replications and 10 plants per treatment (200 polybag seedlings of citrus plants). The treatments tested were biagas waste at $0 \%, 11 \%, 20 \%$, $27 \%$ and $33 \%$. Parameters observed were plant height, stem diameter, number of leaves, number of fruits. The results showed that the higher the use of biogas waste as guava seedling media, the better the plant performance. The best media composition of biogas waste for guava seedling is $33 \%$ biogas waste organic fertilizer.
\end{abstract}

Keywords: Psidium guajava, Organic manure, Growth.

\section{PENDAHULUAN}

Sistem usaha tani di Indonesia sudah sejak lama dan bertahan hingga kini menerapkan sistem integrasi antara tanaman dan ternak. Wahyuni (2011) menyatakan bahwa, limbah ternak yang tidak diolah dengan baik dapat menjadi penghasil rumah kaca. Berdasarkan laporan FAO 2006, salah satu penghasil emisi gas rumah kaca yang terbesar berasal dari sektor peternakan, sebesar $18 \%$. Limbah ternak melalui teknologi biogas, selain dapat dimanfaatkan sebagai sumber energi juga dapat menghasilkan pupuk organik berupa slurry dan sludge (limbah biogas padat dan cair) yang sangat bermanfaat. Menurut Muryanto et al. (2006) dan Islam et al. (2010), limbah biogas adalah pupuk organik yang tepat guna dari limbah peternakan untuk produksi pertanian yang berkelanjutan, ramah lingkungan dan bebas polusi. Limbah biogas dapat meningkatkan produksi pertanian karena kandungan hara, enzim dan hormon pertumbuhan yang terdapat didalamnya (Karki, 2001). Nugroho (2012) menambahkan bahwa pupuk limbah biogas mempunyai manfaat yang sama dengan pupuk kandang yaitu untuk memperbaiki struktur tanah dan memberikan unsur hara yang diperlukan tanaman.

Menurut Gupta et al. (2012), sistem pertanian terpadu seperti integrasi antara tanaman dan ternak memegang posisi penting dalam sistem pertanian lahan kering. Salah satu komoditas tanaman lahan kering adalah tanaman buah-buahan, salah satunya adalah buah jambu biji. Selain sebagai buah meja, jambu biji biji (Psidium guajava) kerap dikonsumsi dalam bentuk jus. Kandungan vitamin C-nya yang tinggi membuat buah ini digemari banyak konsumen. Jus jambu biji biji, terutama yang daging buahnya berwarna merah, juga banyak dijual di Supermarket sebagai jus dalam kemasan.

1) Balai Penelitian Teknologi Pertanian (BPTP) Jawa Tengah

Jl. Soekarno-Hatta Km. 26 No. 10 Bergas, Kab. Semarang

Author contact: aryanacitra@yahoo.co.id
Selain buahnya, beberapa orang kerap memanfaatkan daunnya untuk obat diare Sobir dan Amalya (2002) dan di Jawa Tengah terutama di Banyumas daun jambu biji dimanfaatkan untuk memasak telur dengan tujuan memberikan aroma yang khas dan lezat.

Jambu biji dapat tumbuh dimana saja, tetapi tetap membutuhkan lingkungan yang optimal agar dapat menghasilkan buah yang memuaskan. Tanaman ini dapat tumbuh baik di daerah tropis, terutama pada ketinggian 5-1200 m dpl. Tanaman buah jambu biji biji sebenarnya dapat tumbuh pada semua jenis tanah. Namun idealnya, tanaman ini tumbuh baik pada tanah yang subur dan gembur serta banyak mengandung unsur nitrogen dan bahan organik atau pada tanah liat dan sedikit pasir dengan kemampuan menyerap yang baik. Derajat keasaman tanah $(\mathrm{pH})$ yang diinginkan adalah 6-6,5 (Sobir dan Amalya, 2002).

Benih (biji) dan bibit secara struktural, fungsional, agronomi, dan teknologi memiliki pengertian yang berbeda (Kartasapoetra, 2003), namun Pemerintah memberikan batasan yang lebih luas tentang pengertian benih. Berdasarkan Peraturan Menteri Pertanian No. 39/Permentan/ OT.140/ 8/2006 (Ditjenbun, 2006), yang dimaksud benih yaitu tanaman atau bagiannya yang digunakan untuk memperbanyak dan atau mengembangbiakan tanaman. Berdasarkan pengertian tersebut, maka benih tidak saja identik dengan biji namun bisa bagian tanaman lainnya seperti daun, akar, dan batang. Dengan demikian, pembibitan tanaman buah jambu biji lebih tepat disebut sebagai perbenihan tanaman buah jambu biji.

Pada tahap awal, perbenihan tanaman buah merupakan tahap yang penting awal pertumbuhan sebagai modal benih yang baik untuk dapat menghasilkan pertumbuhan dan hasil yang maksimal pada saat sudah dilahan. Salah satu komponen dalam perbenihan tanaman buah adalah media tanam. Media tanam merupakan salah satu komponen penting dalam perbenihan. Media tanam yang dipakai untuk perbenihan harus sesuai sehingga tanaman bisa tumbuh dengan baik. Masing-masing tanaman memiliki 
karakteristik berbeda-beda, sehingga media tanam yang dibutuhkan juga dapat berbeda-beda.

Sekam padi merupakan media tanam yang dibuat dari kulit padi yang sudah digiling. Media tanam dari sekam yang biasa digunakan bisa berupa sekam mentah dan sekam bakar. Kedua jenis sekam tersebut memiliki tingkat porositas yang sama sehingga bisa memberikan peran penting dalam perbaikan struktur tanah. Kelebihan media tanam dari sekam adalah bisa dengan mudah mengikat air, tidak mudah lapuk dan merupakan sumber kalium yang dibutuhkan oleh tanaman. Selain itu media tanam dari sekam juga tidak mudah menggumpal sehingga akar tanaman bisa tumbuh dengan sempurna. Tapi kelemahan media tanam ini adalah memiliki kandungan unsur hara yang sedikit (Anonim, 2018). Selain penggunaan limbah biogas untuk media tanam belum banyak dilakukan dan dalam rangka memanfaatkan limbah biogas serta memberikan unsur hara pada tanaman buah jambu biji di perbenihan, maka dilakukan penelitian dengan tujuan untuk mengetahui pengaruh pemberian limbah biogas sapi terhadap perbenihan tanaman jambu biji. Manfaat dari penelitian adalah dapat memberikan informasi pemanfaatan limbah biogas terhadap media tanam perbenihan tanaman buah-buahan terutama buah jambu biji.

\section{BAHAN DAN METODE}

Pengkajian dilaksanakan di Dusun Gintungan Desa Gogik Kec. Ungaran Barat Kab. Semarang pada JuliDesember 2015. Metode percobaan yang digunakan adalah Rancangan Acak Kelompok Lengkap (RAKL) dengan 1 faktor yaitu perbandingan komposisi media sebanyak 5 perlakuan dengan 4 ulangan dan 10 tanaman per perlakuan (200 polibag benih tanaman jambu biji). Perlakuan yang dicobakan yaitu: P.0 = Media tanah (tanah sekam 1:1), P.1 = P0 dan pupuk organik limbah biogas 11\%, P.2 = P0 dan pupuk organik limbah biogas 20\%, P.3 = P0 dan pupuk organik limbah biogas $27 \%$ dan P.4 = P0 dan pupuk organik limbah biogas $33 \%$. Parameter yang diamati yaitu tinggi tanaman, diameter batang tunas, jumlah daun, jumlah buah. Pengamatan tanaman dilakukan 2 minggu sekali. Data pertumbuhan tanaman yang diperoleh selama pengkajian dianalisis statistik menggunakan Analisis Ragam Anova. Selanjutnya apabila diantara perlakuan menunjukkan perbedaan yang sangat nyata atau nyata, akan dilanjutkan dengan uji beda nyata terkecil (BNT).

\section{HASIL DAN PEMBAHASAN}

Hasil penelitian menunjukkan bahwa penambahan pupuk organik limbah biogas mampu meningkatkan pertumbuhan benih jambu biji. Hal tersebut sesuai dengan hasil-hasil penelitian mengenai penggunaan limbah biogas. Penggunaan limbah biogas dapat berpengaruh terhadap mikro lingkungan tanah dan berpengaruh terhadap pertumbuhan dan hasil tanaman. Hasil penelitian Utami et al. (2014) dan Gupta (1991) menyatakan bahwa pemberian limbah biogas mampu meningkatkan nilai $\mathrm{pH}$, C-organik dan $\mathrm{N}$ total tanah. Selain itu, limbah biogas juga mampu meningkatkan $\mathrm{P}$ tersedia, $\mathrm{K}$ tersedia dan KPK tanah. Hal ini menunjukkan limbah biogas sapi berpotensi untuk digunakan sebagai pupuk organik. Menurut Tripathi (1993), pemberian limbah biogas dapat meningkatkan kualitas fisik dan biologi tanah, bebas bau, bebas gulma, dan bebas patogen. Limbah biogas menyediakan nutrisi, dan meningkatkan aktivitas mikroflora dalam tanah (Laxmanan, 1993; Singh et al.,1995). Mostarina (2009) menambahkan bahwa limbah biogas mampu meningkatkan status kesuburan tanah dan meningkatkan hasil padi. Majumder (2006) menambahkan bahwa pemberian limbah biogas 20 t/ha mampu memberikan hasil kentang yang lebih tinggi dibandingkan dengan pemberian pupuk kimia. Hasil penelitian Kusumasari et al. (2015) menunjukkan bahwa pemberian limbah biogas pada tanaman jali, singkong, padi, sorgum menunjukkan pertumbuhan dan hasil yang lebih tinggi dibandingkan dengan yang diberi pupuk anorganik.

Komposisi yang dicobakan masih dalam dosis yang sesuai untuk tanaman, karena sampai pada kompisisi penggunaan limbah biogas tertinggi masih menunjukkan hasil yang positif. Oleh karena itu, dosis pemberian limbah biogas masing-masing jenis tanaman, dan masing-masing tahapan perkembangan tanaman kebutuhannya berbeda-beda. Hal ini sesuai dengan penelitian Islam et al. (2010) yang menunjukkan bahwa pemberian limbah biogas yang optimum untuk tanaman jagung terbaik adalah pada dosisi $70 \mathrm{~kg} \mathrm{~N} / \mathrm{ha}$, sedangkan pada dosis $80 \mathrm{~kg} \mathrm{~N} /$ ha pertumbuhan dan hasil jagung menurun. Hasil penelitian Jeptoo et al. (2013) juga menunjukkan bahwa pemberian limbah biogas sapi dapat meningkatkan pertumbuhan tanaman dan hasil wortel serta kualitas wortel seperti panjang, diameter dan tingkat kemanisan wortel. Dosis yang dicobakan dari kontrol tanpa pemberian limbah biogas, dan bertahap dengan interval 2,6 t/ha. Dosis terbaik adalah 5,2 t/ha yang tidak berbeda nyata dengan pemberian $7,8 \mathrm{t} / \mathrm{ha}$.

Hasil perbenihan yang menggunakan limbah biogas menunjukkan hasil yang lebih baik dibandingkan dengan yang hanya tanah dan sekam saja. Hal ini disebabkan karena sekam hampir tidak memiliki kandungan unsur hara, sedangkan kandungan tanah dibandingkan dengan limbah biogas disajikan Tabel 1.

Tabel 1. Perbedaan Karakteristik Tanah dan Limbah Biogas

\begin{tabular}{lcc}
\multicolumn{1}{c}{ Karakteristik } & Tanah & Limbah Biogas \\
\hline Clay (\%) & 20 & - \\
Silt (\%) & 66 & - \\
Pasir (\%) & 14 & - \\
$\begin{array}{l}\text { Tipe tanah } \\
\text { Moisture content }\end{array}$ & Silt loam & - \\
$\begin{array}{l}\text { (\%) } \\
\text { Total nitrogen (mg }\end{array}$ & - & 79 \\
kg-1) & 1,32 & 5,88 \\
$\begin{array}{l}\text { Total phosphorus } \\
\text { (mg kg-1) }\end{array}$ & 1,38 & 2,72 \\
$\begin{array}{l}\text { Total potassium } \\
\text { (mg kg-1) }\end{array}$ & 3,94 & 1,33 \\
$\begin{array}{l}\text { ExtracTabelsulfur } \\
\text { (mg kg-1) }\end{array}$ & 1,02 & 0,79 \\
$\begin{array}{l}\text { Sumber: Islam et al., } 2010 . \\
\end{array}$ &
\end{tabular}


Penambahan pupuk organik limbah biogas dengan dosis yang tinggi yaitu pada perlakuan P.4 menunjukkan respon terbaik pada tinggi tanama, diameter tunas dan jumlah dun (Tabel 2). Berdasarkan hasil analisis ragam perlakuan perbandingan komposisi media tanam terhadap variabel pengamatan tidak berbeda nyata ditunjukkan pada variabel tinggi tanaman pada semua umur pengamatan dan diameter batang tunas umur 2 dan 4 mst. Hasil analisis ragam perlakuan perbandingan komposisi media tanam terhadap variabel pengamatan berbeda nyata pada diameter batang tunas umur 6 dan $8 \mathrm{mst}$, serta jumlah daun umur 2, 4,6 dan $8 \mathrm{mst}$. Dapat disimpulkan bahwa, secara umum pemberian pupuk organik dalam media pembibitan jambu biji memberikan respon yang positif sejalan dengan jumlah pupuk organic yang diberikan. Meskipun masih berupa perbenihan namun tanaman jambu biji ini sudah dapat berbuah. Namun demikian, tanaman jambu biji memerlukan ruang/media tempat tumbuh yang lebih luas dibandingkan di saat perbenihannya, sehingga untuk dapat memproduksi buah dengan maksimal harus dilakukan pindah tanam ke media yang lebih besar atau langsung ke lahan. Produksi buah jambu biji menunjukkan bahwa jumlah buah yang dihasilkan sejalan dengan respon pertumbuhan tanaman, yaitu pada perlakuan P.3 dan P.4 tanaman mampu berbuah pada media perbenihan.

Tabel 2. Pengaruh Perbedaan Komposisi Pupuk Organik terhadap Tinggi Tanaman, Diameter Batang Tunas, dan Jumlah Daun Benih Tanaman Jambu Biji (Psidium guajava)

\begin{tabular}{|c|c|c|c|c|}
\hline \multirow{2}{*}{$\begin{array}{c}\text { Perlakuan } \\
\text { (\%) }\end{array}$} & \multicolumn{4}{|c|}{ Minggu Setelah Tanam } \\
\hline & 2 & 4 & 6 & 8 \\
\hline \multicolumn{5}{|c|}{ Tinggi Tanaman $(\mathrm{Cm})$} \\
\hline 0 & $64,7 \mathrm{a}$ & 78,6 a & 78,9 a & $79,2 \mathrm{a}$ \\
\hline 11 & 73,9 a & $85,2 \mathrm{a}$ & $85,4 \mathrm{a}$ & $90,5 \mathrm{a}$ \\
\hline 20 & $68,1 \mathrm{a}$ & $79,4 \mathrm{a}$ & $80,5 \mathrm{a}$ & $88,5 \mathrm{a}$ \\
\hline 27 & $66,7 \mathrm{a}$ & $80,0 \mathrm{a}$ & $81,5 \mathrm{a}$ & $84,2 \mathrm{a}$ \\
\hline 33 & $71,2 \mathrm{a}$ & $82,0 \mathrm{a}$ & $90,0 \mathrm{a}$ & $91,5 \mathrm{a}$ \\
\hline \multicolumn{5}{|c|}{ Diameter Batang Tunas $(\mathrm{Cm})$} \\
\hline 0 & $8,0 \mathrm{a}$ & $8,4 \mathrm{a}$ & $8,5 \mathrm{a}$ & $8,5 \mathrm{a}$ \\
\hline 11 & $7,7 \mathrm{a}$ & $9,2 \mathrm{a}$ & $9,3 \mathrm{a}$ & $9,3 \mathrm{a}$ \\
\hline 20 & $7,8 \mathrm{a}$ & $8,6 \mathrm{a}$ & $9,0 \mathrm{a}$ & $9,5 \mathrm{a}$ \\
\hline 27 & $7,4 \mathrm{a}$ & $8,6 \mathrm{a}$ & $9,0 \mathrm{a}$ & $9,7 \mathrm{a}$ \\
\hline 33 & $6,5 \mathrm{a}$ & $8,9 \mathrm{a}$ & $9,9 \mathrm{~b}$ & $11,5 \mathrm{~b}$ \\
\hline \multicolumn{5}{|c|}{ Jumlah Daun (buah) } \\
\hline 0 & $24,1 \mathrm{a}$ & $29,7 \mathrm{a}$ & $30,9 \mathrm{a}$ & $34,7 \mathrm{a}$ \\
\hline 11 & $26,8 \mathrm{a}$ & $31,1 \mathrm{a}$ & $31,3 \mathrm{a}$ & $34,7 \mathrm{a}$ \\
\hline 20 & $27,1 \mathrm{a}$ & $29,5 \mathrm{a}$ & $30,4 \mathrm{a}$ & $36,8 \mathrm{a}$ \\
\hline 27 & $28,7 \mathrm{a}$ & $38,0 \mathrm{~b}$ & $38,1 \mathrm{a}$ & $39,9 a$ \\
\hline 33 & $35,7 b$ & $37,1 \mathrm{~b}$ & $40,0 \mathrm{~b}$ & $44.2 \mathrm{~b}$ \\
\hline
\end{tabular}

Keterangan: Angka yang diikuti huruf yang sama dalam kolom tidak berbeda nyata pada taraf $5 \%$ BNT

\section{KESIMPULAN DAN SARAN}

\section{Kesimpulan}

Berdasarkan hasil dan pembahasan dapat disimpulkan sebagai berikut:

1. Limbah biogas dapat digunakan sebagai pupuk organik pada perbenihan tanaman jambu biji.

2. Limbah biogas $33 \%$ meningkatkan jumlah cabang, diameter batang dan jumlah daun

\section{Saran}

Pemakaian limbah biogas 33\% dpt dianjurkan untuk perbenihan jambu biji

\section{DAFTAR PUSTAKA}

Ditjenbun, 2006. Peraturan Menteri Pertanian No. 01/Pert/Sr.120/2/2006 Tentang Syarat Penamaan dan Tata Cara Pendaftaran Varietas Tanaman. www.ditjenbun.pertanian.go.id. Diakses 10 Oktober 2014

Gupta, D.R. 1991. Bio-Fertilizer from Biogas Plants In Changing Villages. 10(I): 122-130.

Gupta, V,. P.K. Rai and K.S. Risam. 2012. Integrated Crop-Livestock Farming Systems: a Strategy for Resource Conservation and Enviromental Sustainbility. Indian Research J. of Extension Education, Special Issue II: 49-54.

Karki, K. B. 2001. Response to bio-slurry Application on Maize and Cabbage in Laliptur District. Final Field Research Report Submitted to Alternative Energy Promotion Centre of Ministry of Science and Technology. Pulchok. Nepal.

Islam M.R, Rahman S.M.E, Rahman M,Md. 2010. The Effects Of Biogas Slurry On The Production And Quality Of Maize Fodder. Turk J Agric For 34 91-99.

Jeptoo A, Aguyohi J.N, dan Saidi M. 2013. Improving Carrot Yield and Quality through the Use of Bio-Slurry Manure. Sustainable Agriculture Research; 2(1). Published by Canadian Center of Science and Education.

Kartasapoetra, A.G. 2003. Teknologi Benih Pengolahan Benih dan Tuntutan Praktikum. Cetakan Ke-4. PT. Rineka Cipta, Jakarta.

Kusumasari, A.C. A. Hermawan, H. Kurnianto, dan Suryanto. 2015. Strategi Pengelolaan Lahan Kering dengan Prinsip SITT sebagai Alternatif Lumbung Pangan. Bagian Buku: Biosiklus Terpadu Padi Sapi di Lahan Irigasi. IAARD Press, Jakarta.

Laxamanan, A.R.; Kuppuswamy, G. and Jeyabal, A. 1993. Use of Biogas Effluents as Seed Coating Media for Successful Crop Production In Biogas Slurry Utilsation. New Delhi CORT.

Majumder T. I. 2006. Slurry Enrichment and Use in vegeTabelcrop. Personal Management.

Mostarina, B. 2009. Effect of Sewage Sludge On The Growth And Yield Of Rice (Cv. BRRI DHAN 33). MS Thesis., Dept. Environ. Sci., Bangladesh Agric. Univ., Mymensingh.

Muryanto, J. Pramono, Suprapto, E. Kushartanti, Sudadiyono. 2006. Biogas. Balai Pengkajian Teknologi Pertanian, Ungaran. 
Nugroho, C. 2012. Macam-Macam Pupuk Organik. Penebar Swadaya, Jakarta.

Singh, Shiv. P.; Verma, H. V.; Vatsa, D. K. and Kalia, A.K. 1995. Effect of Biogas Digested Slurry on Pea, Okra, Soybean and Maize. In Biogas Forum IV(63).

Sobir dan M. Amalya. 2011. Bertanam 20 Buah Koleksi Eksklusif. Penebar Swadaya, Jakarta.

Tripathi, A.K. 1993. Biogas Slurry A Boon for Agriculture Crops In Biogas Slurry Utilisation. New Delhi: CORT.

Utami W.S, B.H. Sunarminto, E. Hanudin. 2014. Pengaruh Limbah Biogas Sapi Terhadap Ketersediaan Hara Makro-Mikro Inceptisol. J. Tanah dan Air 11(1):12-21.

Wahyuni, S. 2011. Menghasilkan Biogas dari Aneka Limbah. Penebar Swadaya, Jakarta. 